\title{
Cassava with enhanced $\beta$-carotene maintains adequate vitamin A status in Mongolian gerbils (Meriones unguiculatus) despite substantial cis-isomer content
}

\author{
Julie A. Howe ${ }^{1,2}$, Bussie Maziya-Dixon ${ }^{3}$ and Sherry A. Tanumihardjo ${ }^{1 *}$ \\ ${ }^{1}$ Department of Nutritional Sciences, University of Wisconsin-Madison, Madison, WI 53706, USA \\ ${ }^{2}$ Department of Agronomy and Soils, Auburn University, Auburn, AL 36849, USA \\ ${ }^{3}$ International Institute for Tropical Agriculture (IITA), P.M.B. 5320, Ibadan, Nigeria \\ (Received 2 October 2008 - Revised 13 November 2008 - Accepted 17 November 2008 - First published online 13 January 2009)
}

Efforts to increase $\beta$-carotene in cassava have been successful, but the ability of high- $\beta$-carotene cassava to prevent vitamin A deficiency has not been determined. Two studies investigated the bioefficacy of provitamin A in cassava and compared the effects of carotenoid content and variety on vitamin A status in vitamin A-depleted Mongolian gerbils (Meriones unguiculatus). Gerbils were fed a vitamin A-free diet 4 weeks prior to treatment. In Expt 1, treatments (ten gerbils per group) included $45 \%$ high- $\beta$-carotene cassava, $\beta$-carotene and vitamin A supplements (intake matched to high- $\beta$-carotene cassava group), and oil control. In Expt 2, gerbils were fed cassava feeds with 1.8 or $4.3 \mathrm{nmol}$ provitamin A/g prepared with two varieties. Gerbils were killed after 4 weeks. For Expt 1 , liver vitamin A was higher $(P<0.05)$ in the vitamin A (1.45 (SD 0.23) $\mu$ mol/ liver), lower in the control (0.43 (SD 0.10) $\mu \mathrm{mol} /$ liver), but did not differ from the $\beta$-carotene group (0.77 (SD 0.12$) \mu \mathrm{mol} / \mathrm{liver}) \mathrm{when}$ compared with the high- $\beta$-carotene cassava group (0.69 (SD 0.20) $\mu \mathrm{mol} / \mathrm{liver}$ ). The bioconversion factor was $3.7 \mu \mathrm{g} \beta$-carotene to $1 \mu \mathrm{g}$ retinol ( $2 \mathrm{~mol}: 1 \mathrm{~mol})$, despite $48 \%$ cis- $\beta$-carotene [(Z)- $\beta$-carotene] composition in cassava. In Expt 2 , cassava feed with $4.3 \mathrm{nmol}$ provitamin A/g maintained vitamin A status. No effect of cassava variety was observed. Serum retinol concentrations did not differ. $\beta$-Carotene was detected in livers of gerbils receiving cassava and supplements, but the cis-to-trans ratio in liver differed from intake. Biofortified cassava adequately maintained vitamin A status and was as efficacious as $\beta$-carotene supplementation in the gerbil model.

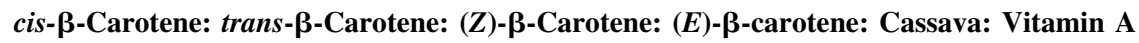

Vitamin A deficiency is a major health problem particularly in Africa and South-East Asia where foods rich in preformed vitamin A (e.g. milk, eggs and liver) or provitamin A (e.g. carrots, sweet potato and pumpkin) are lacking. Deficiencies can result in blindness, night blindness, decreased immunity, and increased morbidity and mortality. Due to the essential role of vitamin A in reproduction and growth, women and children are particularly affected.

Cassava is a staple food for many populations at risk for vitamin A deficiency, especially in Africa. In cassava, $\beta$-carotene is the primary provitamin A carotenoid, but concentrations in typical white cassava are low, about $1 \mu \mathrm{g} / \mathrm{g}$ fresh weight or about $3 \mu \mathrm{g} / \mathrm{g}$ dry weight ${ }^{(1,2)}$. Ongoing efforts to breed cassava for increased provitamin A have identified genotypes with more than $10 \mu \mathrm{g} \beta$-carotene/g fresh weight ${ }^{(2)}$. These concentrations are still low compared to typical carrot, i.e. $130 \mu \mathrm{g}$ $\beta$-carotene/g fresh weight ${ }^{(3)}$. Low predicted bioconversion rates of $\beta$-carotene to vitamin A (i.e. $12 \mu \mathrm{g}$ to $1 \mu \mathrm{g}$ all-trans retinol (i.e. all- $(E)$-retinol) proposed by the Institute of Medicine ${ }^{(4)}$ ) and generally poor bioavailability of provitamin A carotenoids from food ${ }^{(4,5)}$ further contribute to questions regarding the bioefficacy of biofortified cassava.
Bioavailability of provitamin A carotenoids from foods is not well understood. Before breeding efforts continue, it is essential to assess whether carotenoid-biofortified cassava can positively contribute to vitamin A status. Many factors influence carotenoid absorption and bioconversion ${ }^{(6)}$. Lack of methodology to directly measure absolute bioavailability further complicates the issue. Measuring change in serum carotenoid concentrations following intervention has been used ${ }^{(5)}$. Results from this approach are affected by carotenoid and vitamin A regulation in the blood and bioconversion of provitamin A to vitamin A preceding entry into the bloodstream ${ }^{(7)}$. Serum carotenoid assessment is also influenced by the amount of carotenoid administered in the dose or meal, presence of adequate fat during adsorption, and vitamin $\mathrm{A}$ status due to its regulation of the conversion of $\beta$-carotene to vitamin $A^{(8-11)}$.

Other methods have been used to evaluate provitamin A bioavailability. The most common methods include in vitro intestinal cell methods ${ }^{(12-15)}$, stable isotope tracers ${ }^{(16,17)}$ and animal models ${ }^{(18-21)}$. In vitro models using Caco- 2 cells best model bioaccessibility and do not reflect enzymatic regulation of bioconversion. Isotope tracer studies in man are perhaps the best $\operatorname{method}^{(17)}$, but many experimental factors such as diet and 
vitamin A status are difficult to control. Appropriate animal models provide a lower-cost alternative with greater experimental control. In addition, the use of animal models permits direct measurement of liver vitamin $\mathrm{A}$, which is considered the best indicator of vitamin A status ${ }^{(22)}$, and allows calculation of true bioefficacy. For carotenoids, rats and mice are not appropriate because unlike man, they absorb very little $\beta$-carotene intact $^{(18-20)}$. In contrast, the Mongolian gerbil absorbs and metabolises $\beta$-carotene similarly to $\operatorname{man}^{(21,23-26)}$.

The objective of the present research was to investigate the bioefficacy of $\beta$-carotene from biofortified cassava in Mongolian gerbils with depleted vitamin A status. The high cis- $\beta$ carotene (i.e. ( $Z$ )- $\beta$-carotene) content of processed cassava provided an opportunity to examine the effect of the cis isomer on bioconversion to vitamin A. Two studies were conducted in parallel to compare the bioefficacy of $\beta$-carotene from cassava with vitamin $\mathrm{A}$ and $\beta$-carotene supplements (Expt 1) and to investigate the effect of dietary level and cassava variety on vitamin A status (Expt 2).

\section{Materials and methods}

\section{Cassava and feeds}

Three cassava varieties (white, \#1 and \#2) were crated and shipped from the International Institute of Tropical

(Mean values and standard deviations)
Agriculture in Nigeria. Upon arrival, damaged tubers were discarded, and remaining tubers were peeled, cut into approximately $2-3 \mathrm{~cm}$ slices, boiled for $30 \mathrm{~min}$, cooled and frozen at $-20^{\circ} \mathrm{C}$. The cassava varieties used were low in cyanogenic compounds and ranged from 13 to $45 \mathrm{mg}$ cyanide equivalents/100g fresh weight, which were removed by boiling sliced tubers in a large amount of water. Frozen cassava was then freeze-dried and ground into a powder with a coffee grinder. High $\beta$-carotene cassava varieties were stored at $-80^{\circ} \mathrm{C}$ and white cassava was stored at $-20^{\circ} \mathrm{C}$. All varieties were analysed for carotenoid concentration (Table 1) and used to prepare seven powdered Mongolian gerbil feeds with variable cassava (Table 2) and carotenoid compositions (Table 3).

With the assistance of Harlan-Teklad (Madison, WI, USA), gerbil feeds were designed to use cassava as the carbohydrate source. For the vitamin A-depletion phase, the vitamin A- and carotenoid-free feed was $30 \%$ white cassava (Table 2). For the treatment phase of the first experiment, feeds were $45 \%$ white or cassava \#1. For the second experiment, feeds were 40 and $17 \%$ cassava \#1 and 35 and $15 \%$ cassava \#2 (Table 2). High and low cassava percentages were designed to equalise the $\beta$-carotene concentrations from cassava \#1 and \#2. Differences in the percentage cassava among feeds were offset with sucrose-starch $(2: 1)$. Because synthetic vitamin $\mathrm{A}$ and provitamin A carotenoids were not added to the feeds, the only source of vitamin A was from the cassava.

Table 1. Carotenoid concentrations (nmol/g dry weight cassava) in three varieties of cassava

\begin{tabular}{|c|c|c|c|c|c|c|c|c|c|}
\hline \multirow[b]{2}{*}{ Cassava variety } & \multicolumn{2}{|c|}{$\alpha$-Carotene } & \multicolumn{2}{|c|}{$\begin{array}{l}\text { trans- } \beta- \\
\text { Carotene }\end{array}$} & \multicolumn{2}{|c|}{$\begin{array}{l}\text { 9-cis- } \beta \text { - } \\
\text { Carotene }\end{array}$} & \multicolumn{2}{|c|}{$\begin{array}{l}\text { 13-cis- } \beta- \\
\text { Carotene }\end{array}$} & \multirow[b]{2}{*}{ Total theoretical retinol} \\
\hline & Mean & SD & Mean & SD & Mean & SD & Mean & SD & \\
\hline White & 0.01 & 0.001 & 0.37 & 0.02 & 0.01 & 0.001 & 0.19 & 0.001 & $1 \cdot 15$ \\
\hline$\# 1$ & 0.32 & 0.02 & $5 \cdot 68$ & 0.40 & 1.68 & 0.22 & 2.59 & 0.21 & $20 \cdot 2$ \\
\hline \#2 & 0.44 & 0.01 & $5 \cdot 87$ & 0.12 & $2 \cdot 72$ & 0.36 & 2.79 & 0.06 & $23 \cdot 2$ \\
\hline
\end{tabular}

* Theoretical vitamin A assumes $1 \mathrm{~mol} \beta$-carotene provides $2 \mathrm{~mol}$ retinol and $1 \mathrm{~mol} \alpha$-carotene provides $1 \mathrm{~mol}$ retinol.

Table 2. Composition of experimental feeds ( $\mathrm{g} / \mathrm{kg}$ feed) fed to Mongolian gerbils (Meriones unguiculatus) differing by cassava content*

\begin{tabular}{|c|c|c|c|c|c|c|}
\hline & \multicolumn{6}{|c|}{ Cassava content (\%) } \\
\hline & 45 & 40 & 35 & 30 & 17 & 15 \\
\hline Cassava & 450 & 403 & 350 & 300 & 172 & 150 \\
\hline Vitamin-free casein & 363 & 363 & 363 & 363 & 363 & 363 \\
\hline L-Cystine & 5.45 & 5.45 & 5.45 & 5.45 & 5.45 & 5.45 \\
\hline Sucrose & $219 \cdot 0$ & $250 \cdot 3$ & $285 \cdot 7$ & 320 & $404 \cdot 3$ & $419 \cdot 0$ \\
\hline Maize starch & $110 \cdot 0$ & $125 \cdot 7$ & $143 \cdot 3$ & 160 & $202 \cdot 7$ & $230 \cdot 0$ \\
\hline Cottonseed oil & $109 \cdot 0$ & $109 \cdot 0$ & $109 \cdot 0$ & $109 \cdot 0$ & $109 \cdot 0$ & $109 \cdot 0$ \\
\hline Cellulose & $109 \cdot 0$ & $109 \cdot 0$ & $109 \cdot 0$ & $109 \cdot 0$ & $109 \cdot 0$ & $109 \cdot 0$ \\
\hline Mineral mix $†$ & 63.64 & 63.64 & 63.64 & 63.64 & 63.64 & 63.64 \\
\hline $\mathrm{MgO}$ & $3 \cdot 18$ & $3 \cdot 18$ & $3 \cdot 18$ & $3 \cdot 18$ & $3 \cdot 18$ & $3 \cdot 18$ \\
\hline Vitamin mix $\ddagger$ & $9 \cdot 1$ & $9 \cdot 1$ & $9 \cdot 1$ & $9 \cdot 1$ & $9 \cdot 1$ & $9 \cdot 1$ \\
\hline Vitamin D & 0.0008 & 0.0008 & 0.0008 & 0.0008 & 0.0008 & 0.0008 \\
\hline Vitamin $E$ & 0.44 & 0.44 & 0.44 & 0.44 & 0.44 & 0.44 \\
\hline Choline bitartrate & 4.55 & 4.55 & 4.55 & 4.55 & 4.55 & 4.55 \\
\hline
\end{tabular}

* Provided by Harlan-Teklad, Madison, WI, USA.

† AIN-93M-MX ${ }^{(27)}$.

$\ddagger$ Vitamin mix provided the following ( $\mathrm{mg} / \mathrm{kg}$ feed): biotin, 0.4 ; calcium panthothenate, 66.1 ; folic acid, 2; inositol, 110.1; menadione, 49.6; niacin, 99.1; $p$-aminobenzoic acid, 110.1; pyridoxine- $\mathrm{HCl}$, 22; riboflavin, 22; thiamin- $\mathrm{HCl}, 22$; vitamin $\mathrm{B}_{12}(0.1 \%$ in mannitol), 29.7; ascorbic acid $(97.5 \%), 1016 \cdot 6$. 
Table 3. Treatment groups, carotenoid concentrations and theoretical daily retinol intake for two studies performed in Mongolian gerbils (Meriones unguiculatus)*

(Mean values and standard deviations)

\begin{tabular}{|c|c|c|c|c|c|c|c|c|c|c|}
\hline \multirow[b]{2}{*}{ Cassava in feed (\%) } & \multirow[b]{2}{*}{ Dose } & \multicolumn{2}{|c|}{$\begin{array}{c}\alpha \text {-Carotene } \\
\text { (nmol/g feed) }\end{array}$} & \multicolumn{2}{|c|}{$\begin{array}{l}\text { trans- } \beta \text {-Carotene } \\
(\mathrm{nmol} / \mathrm{g} \text { feed })\end{array}$} & \multicolumn{2}{|c|}{$\begin{array}{l}\text { 9-cis- } \beta \text {-Carotene } \\
\text { (nmol/g feed) }\end{array}$} & \multicolumn{2}{|c|}{$\begin{array}{c}\text { 13-cis- } \beta \text {-Carotene } \\
\text { (nmol/g feed })\end{array}$} & \multirow{2}{*}{$\begin{array}{l}\text { Theoretical retinol } \\
\text { intake }(\mathrm{nmol} / \mathrm{d}) \dagger\end{array}$} \\
\hline & & Mean & SD & Mean & SD & Mean & SD & Mean & SD & \\
\hline \multicolumn{11}{|l|}{ Expt 1} \\
\hline $45 \%$ white & Oil & 0.01 & 0.004 & 0.15 & 0.01 & 0.04 & 0.01 & 0.06 & 0.01 & 3.0 \\
\hline $45 \% \# 1$ & Oil & 0.14 & 0.003 & $2 \cdot 74$ & 0.06 & $1 \cdot 28$ & 0.03 & $1 \cdot 21$ & 0.03 & $62 \cdot 6$ \\
\hline $45 \%$ white & $\beta C$ & 0.01 & 0.004 & 0.15 & 0.01 & 0.04 & 0.01 & 0.06 & 0.01 & 64.6 \\
\hline $45 \%$ white & VA & 0.01 & 0.004 & 0.15 & 0.01 & 0.04 & 0.01 & 0.06 & 0.01 & 64.6 \\
\hline \multicolumn{11}{|l|}{ Expt 2} \\
\hline $40 \% \# 1$ & - & 0.13 & 0.02 & 2.47 & 0.11 & 0.75 & 0.05 & 1.07 & 0.06 & 55.7 \\
\hline $35 \% \# 2$ & - & 0.18 & 0.004 & $2 \cdot 11$ & 0.07 & 0.96 & 0.06 & 0.94 & 0.03 & $52 \cdot 6$ \\
\hline $17 \% \# 1$ & - & 0.06 & 0.003 & 1.01 & 0.03 & 0.28 & 0.03 & 0.42 & 0.002 & $22 \cdot 2$ \\
\hline $15 \%$ \#2 & - & 0.08 & 0.02 & 0.97 & 0.03 & 0.44 & 0.05 & 0.43 & 0.02 & $24 \cdot 1$ \\
\hline
\end{tabular}

$\beta C, \beta$-carotene; VA, vitamin A.

${ }^{*}$ For details of procedures and diets, see the Materials and methods section and Tables 1 and 2 .

† Theoretical retinol intakes for $45 \%$ cassava \#1 group in Expt 1 are calculated from actual feed consumption and carotenoid composition over $28 \mathrm{~d}$. Intakes for other treatment groups in Expt 1 represent the mean daily provitamin A dose supplied to the animal. Doses were equalised daily based on mean feed consumption by the $45 \%$ cassava \#1 group (approximately $5.9 \mathrm{~g} / \mathrm{d}$ ). The contribution of provitamin A in white cassava, $3 \mathrm{nmol} / \mathrm{d}$, was added to daily theoretical retinol intake in feeds with white cassava. In Expt 2 , theoretical retinol intakes were calculated based on a mean feed consumption of $6.4 \mathrm{~g} / \mathrm{d}$. All calculations assume $100 \%$ bioefficacy of provitamin $A$, i.e. $1 \mathrm{~mol} \beta$-carotene provides $2 \mathrm{~mol}$ retinol and $1 \mathrm{~mol} \alpha$-carotene provides $1 \mathrm{~mol}$ retinol.

Feeds were stored at $-20^{\circ} \mathrm{C}$ to prevent carotenoid degradation during the treatment phase.

\section{Carotenoid composition of cassava and feeds}

Cassava and feeds were analysed for carotenoid concentrations (Tables 1 and 3) according to published procedures ${ }^{(28)}$. Because this method was developed for maize and required saponification at $85^{\circ} \mathrm{C}$, variations of the method were performed to verify the use of high temperature and saponification on carotenoid extraction. Results showed no difference in extracted carotenoids saponified at $60^{\circ} \mathrm{C}$ compared with $85^{\circ} \mathrm{C}$, but $5-$ $10 \%$ less carotenoid was extracted without saponification (at room temperature and $60^{\circ} \mathrm{C}$ ) and with saponification at room temperature. Analysis of extracted carotenoids was adapted from published procedures ${ }^{(28-30)}$. A Waters HPLC system (Waters Corporation, Milford, MA, USA) consisting of a guard column, C30 YMC carotenoid column $(4.6 \times 250 \mathrm{~mm}$, $3 \mu \mathrm{m}), 1525$ binary HPLC pump, 717 autosampler, and either a 996 or 2996 photodiode array detector was used. Solvent A consisted of methanol-water $(92: 8, \mathrm{v} / \mathrm{v})$ with $10 \mathrm{mM}-$ ammonium acetate. Solvent B was $100 \%$ methyl-tertiarybutyl ether. Gradient elution was performed at $1 \mathrm{ml} / \mathrm{min}$ with a 30 min linear gradient from 70 to $40 \%$ A. Positive identification of lutein, zeaxanthin, $\beta$-cryptoxanthin and $\beta$-carotene was determined using purified standards and absorption spectra. Chromatograms were generated at $450 \mathrm{~nm}$.

\section{Animals and procedures}

Male $40 \mathrm{~d}$ old Mongolian gerbils ( $n$ 87) were obtained from Charles River Laboratories (Kingston, NY, USA). Gerbils were individually housed in plastic cages and given free access to food and water. Gerbils were weighed daily and monitored for health until all were thriving, at which time, they were weighed every $2 \mathrm{~d}$. Three gerbils died during the first 2 weeks due to self-injury or unwillingness to adapt to depletion feed. After the 4-week depletion phase, six gerbils were killed at baseline. Remaining gerbils were sorted into weight-matched treatment groups (nine or ten per group) and placed on their respective feeds. After 4 weeks, gerbils were killed by exsanguination through direct cardiac puncture while under isoflurane anaesthesia. Blood samples were centrifuged $(2200 \mathrm{~g})$ for $15 \mathrm{~min}$ in $\mathrm{BD}$ Vacutainer $^{\mathrm{TM}} \mathrm{Gel}$ and Clot Activator tubes (Becton Dickinson; Franklin Lakes, NJ, USA) for serum isolation. Livers were excised and stored at $-80^{\circ} \mathrm{C}$ until vitamin A and carotenoid analysis. All animal handling procedures were approved by University of Wisconsin-Madison's Research Animal Resource Center.

\section{Experimental design}

Expt 1. Dietary treatment groups included $45 \%$ cassava \#1 dosed with cottonseed oil, $45 \%$ white cassava supplemented with $\beta$-carotene in oil, $45 \%$ white cassava supplemented with vitamin $\mathrm{A}$ in oil, and $45 \%$ white cassava dosed with oil as a negative control (Table 3). Vitamin A (as retinyl acetate) and $\beta$-carotene in oil doses were equalised to the total daily provitamin A consumption of the $45 \%$ cassava \#1 group assuming that $1 \mathrm{~mol} \beta$-carotene provides $2 \mathrm{~mol}$ vitamin $\mathrm{A}$ and $1 \mathrm{~mol} \alpha$ carotene provides $1 \mathrm{~mol}$ vitamin A (i.e. $100 \%$ bioefficacy). Dosing was performed twice daily approximately $5 \mathrm{~h}$ apart to expand the absorption period for vitamin $\mathrm{A}$ and $\beta$-carotene.

Expt 2. Treatment groups received either $1.8 \mathrm{nmol}$ provitamin A/g feed from $17 \%$ cassava \#1 and $15 \%$ cassava \#2 or $4.3 \mathrm{nmol}$ provitamin $\mathrm{A} / \mathrm{g}$ feed from $40 \%$ cassava \#1 and $35 \%$ cassava \#2 (Table 3 ).

\section{Preparation of $\beta$-carotene and vitamin A supplements for Expt 1}

Oil doses were prepared by dissolving a $\beta$-carotene supplement (GNC Inc., Pittsburg, PA, USA) or retinyl acetate (Sigma, St Louis, MO, USA) into cottonseed oil using 
sonication. Purity of supplements were determined to be $>95 \%$ all-trans- $\beta$-carotene and $>99 \%$ all-trans-retinyl acetate. Final concentrations of $\beta$-carotene and vitamin $\mathrm{A}$ in oil were determined by dissolving an aliquot in hexanes and calculating the concentration using the $E_{\mathrm{lcm}}^{1 \%}(2592$ for $\beta$-carotene and 1845 for vitamin A) at 450 and $325 \mathrm{~nm}$, respectively. The oil doses delivered $0.405 \mathrm{nmol} \beta$-carotene $/ \mu \mathrm{l}$ and $0.795 \mathrm{nmol}$ vitamin $\mathrm{A} / \mu \mathrm{l}$.

\section{Serum and liver preparation for HPLC}

All samples were analysed under gold fluorescent lights to prevent photo-oxidation and isomerisation. Retinyl butyrate (31 $\mu \mathrm{M}$ in methanol) was synthesised and added as an internal standard to determine extraction efficiency in serum (92 (SD 8) $\%$ ) and liver (88 (SD 13) \%). It was also used externally for quantification of retinol and retinyl esters. Modified published procedures were used for vitamin $A$ and $\beta$-carotene analysis of serum and liver ${ }^{(31-33)}$. Serum $(500 \mu \mathrm{l})$ was extracted three times with hexane $(1 \mathrm{ml})$ and dried under argon. Liver $(0.7-$ $0.9 \mathrm{~g}$ ) was ground with approximately $3-5 \mathrm{~g}$ anhydrous sodium sulphate, extracted repeatedly with dichloromethane, and filtered into a $50 \mathrm{ml}$ volumetric flask. An aliquot $(5 \mathrm{ml})$ of the liver extract was dried under argon. Dried serum and liver samples were reconstituted in $100 \mu$ l methanol-dichloroethane $(50: 50, \mathrm{v} / \mathrm{v})$ and injected $(50 \mu \mathrm{l})$ into the HPLC system described previously using a Resolve ${ }^{\mathrm{TM}} \mathrm{C} 18$ column $(5 \mu \mathrm{m}$, $3.9 \times 300 \mathrm{~mm}$; Waters Corporation, Milford, MA, USA). Total liver vitamin A reserves were calculated by summing retinol and all identifiable retinyl esters using photo-diode array detection.

\section{Statistical analysis and calculations}

Data were analysed using Minitab 15.1.0 (Minitab Inc., State College, PA, USA). Outcomes of interest including gerbil weights, serum retinol concentration, and liver vitamin A and $\beta$-carotene content and concentrations were evaluated using ANOVA at $\alpha<0.05$. Differences between treatment groups were determined using least significant differences at $\alpha<0.05$.

\section{Results}

\section{Carotenoid concentration of feeds and feed consumption}

The $30 \%$ white cassava feed used for the vitamin A depletion phase of the experiments contained $0.17 \mathrm{nmol} \beta$-carotene $/ \mathrm{g}$. $\beta$-Carotene concentrations in the treatment feeds ranged from $0.25(\mathrm{SD} 0.01)$ in the white cassava feed to 5.23 (SD 0.06) $\mathrm{nmol} / \mathrm{g}$ feed in the $45 \%$ cassava \#1 group (Table 3). Feed intake during the treatment phase did not differ among groups $(P=0.43)$ and was $5.9($ SD 1.2$)$ and 6.4 (SD 1.7) g/d for Expt 1 and Expt 2, respectively.

\section{Gerbil weights}

Gerbils in the baseline group ( $n$ 6) weighed 66.3 (SD 5.1) g at 4 weeks. One gerbil injured himself and was euthanised $1.5 \mathrm{~d}$ prior to kill, but was included in all analyses except serum retinol. Gerbil weight gain began to plateau at approximately
5 weeks. For all treatment groups, final gerbil weights did not differ $(P=0.32)$ and ranged from $72.2(\mathrm{SD} 4.9)$ to 74.6 (SD 4.7) $\mathrm{g}$ in the $45 \%$ white cassava and $45 \%$ cassava \#1 groups, respectively.

\section{Serum and liver vitamin $A$ and carotenoid concentrations}

Serum retinol concentrations (1.35 (SD 0.20) $\mu \mathrm{mol} / \mathrm{l})$ did not differ among treatment groups whether the studies were considered alone $(P=0.95$ Expt 1 and $P=0.70$ Expt 2$)$ or combined $(P=0.98)$ and ranged from 1.30 (SD 0.13$)$ to 1.39 (SD 0.28$)$ $\mu \mathrm{mol} / \mathrm{l}$ in the $40 \%$ cassava $\# 1$ and oil control groups, respectively. No carotenoids were detected in the serum.

Expt 1. As expected, total hepatic vitamin A was greater in the vitamin A supplement group compared with the other groups (Fig. 1(A); $P<0.001$ ). Total hepatic vitamin $\mathrm{A}$ in the $45 \%$ cassava $\# 1$ and $\beta$-carotene supplement groups did not differ $(P=0 \cdot 82)$ and was approximately half of the vitamin A supplement group. Total hepatic vitamin A in the $45 \%$ cassava \#1 $(P=0.009), \beta$-carotene $(P=0.004)$ and vitamin A $(P<0.001)$ groups was higher than the control due to continued vitamin A depletion during the treatment phase. The baseline group did not differ from $45 \%$ cassava $\# 1, \quad \beta$-carotene or control groups. Differences between groups were similar on a liver concentration basis, except that the $45 \%$ cassava \#1 group did not differ from the control (Fig. 1 (B); $P=0 \cdot 096$ ).

Both cis- and trans- $\beta$-carotene were measured in the liver of gerbils fed $\beta$-carotene from cassava or $\beta$-carotene supplements (Fig. 1(C)). The total and trans- $\beta$-carotene content did not differ between the two groups $(P=0.75$ and $P=0 \cdot 87$, respectively), but cis- $\beta$-carotene was greater in the $\beta$-carotene group than the $45 \%$ cassava \#1 group $(P=0 \cdot 044)$. Results on a concentration basis are not shown, but were similar to total liver content.

Retinol conversion factors were calculated for Expt 1. Bioconversion of $\beta$-carotene to vitamin $\mathrm{A}$ was calculated using the stored hepatic vitamin A (total liver vitamin A of treatment group minus control group). Conversion factors were $3.7 \mu \mathrm{g}$ $\beta$-carotene to $1 \mu \mathrm{g}$ retinol (3.7:1 (2.0:1 on a molar basis)) for the $45 \%$ cassava \#1 group and 2.8:1 (1.5:1 on a molar basis) for the $\beta$-carotene supplement group. Similar conversion factors were obtained when calculated as net intake of provitamin A as $\beta$-carotene divided by the sum of liver storage and use (estimated from the difference of the baseline and control groups).

Percentage liver vitamin A storage was calculated by subtracting the hepatic vitamin A content of the control group from each treatment group and dividing by the vitamin A intake as theoretical retinol minus the intake of the control group. Contribution of liver $\beta$-carotene was ignored due to its low content compared to vitamin A. Percentage liver vitamin A storage did not differ between the $45 \%$ cassava \#1 and $\beta$-carotene supplement groups (16 and $20 \%$, respectively). The vitamin A group had the highest percentage liver storage $(59 \%)$, which was greater than any other treatment group $(P<0 \cdot 001)$.

Expt 2. Total hepatic vitamin A did not differ among cassava or baseline groups, although gerbils receiving lower $\beta$-carotene had lower hepatic vitamin A (Fig. 2(A)). Gerbils receiving the $35-40 \%$ cassava had greater total hepatic 

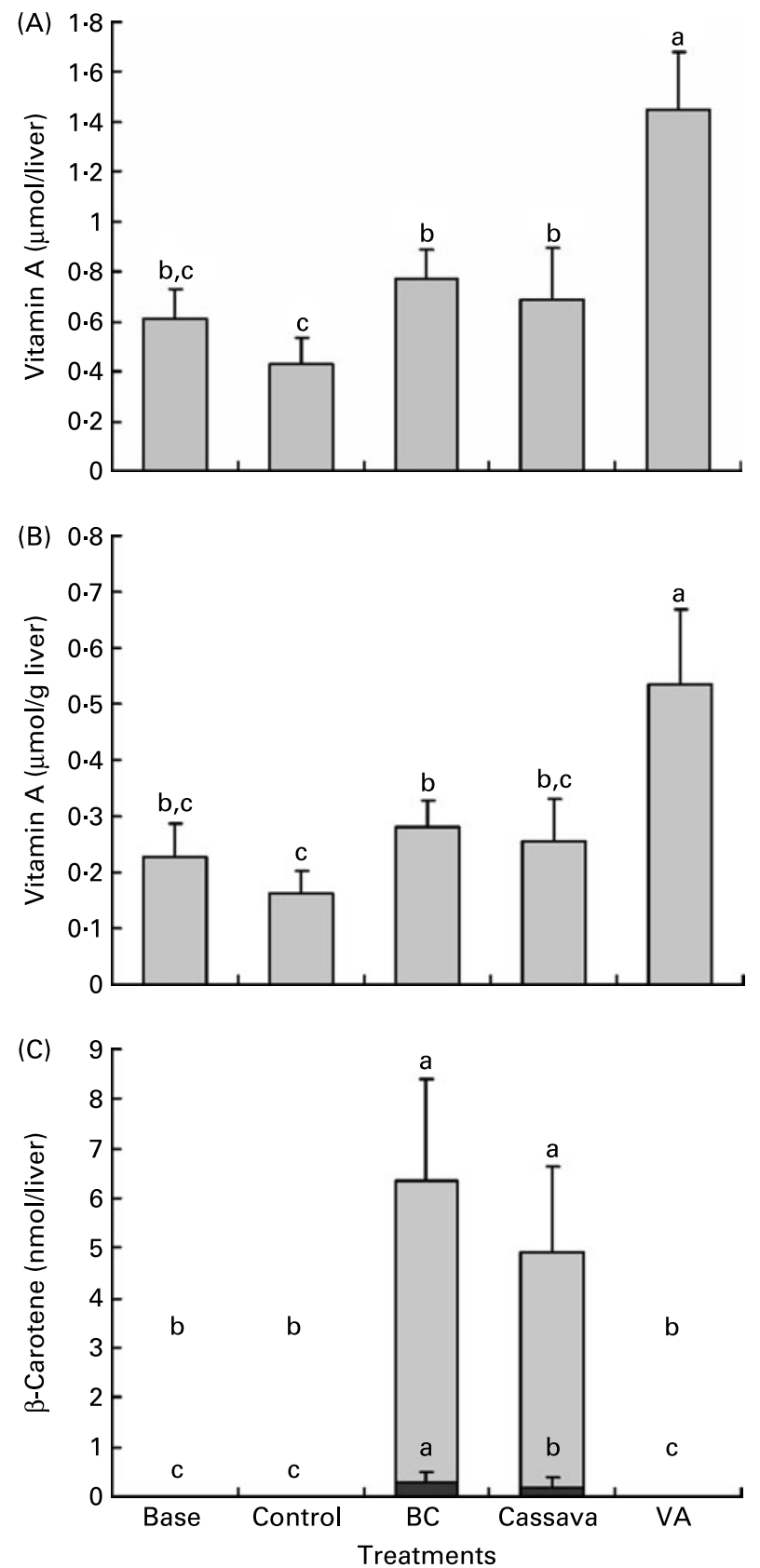

Fig. 1. Total liver vitamin $A(A)$, liver vitamin $A$ concentrations (B) and total $\beta$-carotene per liver $(C)$ of vitamin A-depleted Mongolian gerbils (Meriones unguiculatus) at baseline (Base) and after 4 weeks of treatment including: $45 \%$ white cassava feed with oil (Control), $45 \%$ white cassava with $\beta$-carotene in oil (BC), $45 \%$ high- $\beta$-carotene cassava \#1 feed with oil (Cassava) and $45 \%$ white cassava with vitamin $A$ in oil (VA) from Expt 1. $\beta$-Carotene and vitamin $A$ doses were equalised to the $\beta$-carotene consumption in the $45 \%$ high- $\beta$-carotene cassava group on the prior day assuming $100 \%$ bioconversion of $\beta$-carotene to retinol. Doses were divided by two and administered $5 \mathrm{~h}$ apart. Values are means with standard deviations depicted by vertical bars ( $n 10$ for treatment groups and $n 6$ for baseline). a,b Mean values with unlike letters were significantly different $(P<0.05)$. (C), Upper letters represent differences of total and trans- $\beta$-carotene $(\square)$ and lower letters represent differences of cis- $\beta$-carotene ( $\mathbf{\square})$.

vitamin A than gerbils in the control group $(P=0.017$ and $0 \cdot 001$, respectively), but did not differ with other treatment groups or the baseline group. Hepatic vitamin A content of gerbils receiving $15-17 \%$ cassava feeds did not differ from
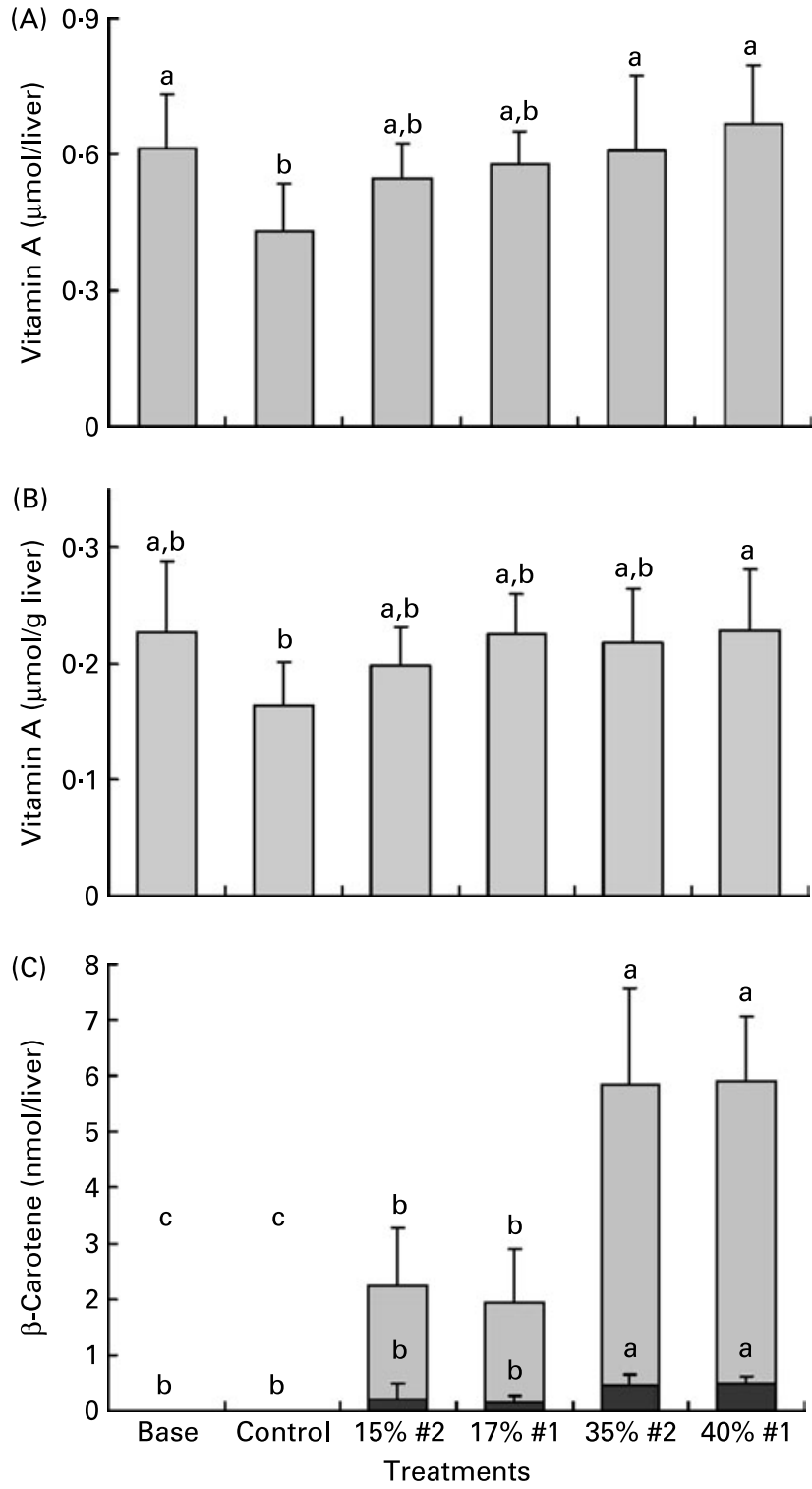

Fig. 2. Total liver vitamin $A(A)$, liver vitamin $A$ concentrations (B) and total $\beta$-carotene $(C)$ of vitamin A-depleted Mongolian gerbils (Meriones unguiculatus) at baseline (Base) and after 4 weeks of cassava treatment including $45 \%$ white cassava (Control), 15\% cassava \#2 (15\% \#2), 17\% cassava \#1 (17\% \#1), $35 \%$ cassava \#2 (35\% \#2) or $40 \%$ cassava \#1 (40\% \#1) feeds from Expt 2. Values are means with standard deviations depicted by vertical bars (n 7-10). ${ }^{\mathrm{a}, \mathrm{b}}$ Mean values with unlike letters were significantly different $(P<0.05)$. (C), Upper letters represent differences of total and trans- $\beta$-carotene $(\square)$ and lower letters represent differences of cis- $\beta$-carotene ( $\square$ ).

control or baseline groups. Hepatic vitamin A concentrations did not differ among cassava and baseline groups. The $40 \%$ cassava group had higher hepatic vitamin A concentrations than the control group $(P=0 \cdot 027)$. All gerbils were considered to have a sufficient vitamin A status, defined as $>0.07 \mu \mathrm{mol} / \mathrm{g}$ liver $^{(34)}$.

Total hepatic $\beta$-carotene (cis, trans and total) was higher in groups receiving $35-40 \%$ cassava $(P<0.001$; Fig. $2(\mathrm{C})$ ). Hepatic total and trans- $\beta$-carotene in gerbils receiving $15-$ $17 \%$ cassava feeds was greater than baseline and control groups $(P<0 \cdot 001)$, but $c i s-\beta$-carotene did not differ from baseline or control groups $(P>0 \cdot 15)$. Results for cis-, trans- and 
total $\beta$-carotene concentrations were consistent with total content and are not shown. No effect of cassava variety was observed for liver vitamin A or $\beta$-carotene. Percentage liver vitamin A storage was calculated for the combined 15-17\% and $35-40 \%$ treatment groups because varieties were fed at equivalent provitamin A concentrations and did not differ. Percentage liver vitamin A storage differed between the 15$17 \%$ cassava and $35-40 \%$ cassava and was 24 and $15 \%$, respectively $(P=0.02)$.

\section{Discussion}

Cassava is consumed through a variety of snacks and main dishes ${ }^{(35)}$, and with enhanced $\beta$-carotene, it has the potential to positively alter vitamin A status. To evaluate bioefficacy, $\beta$-carotene from biofortified cassava was compared with $\beta$-carotene and vitamin A supplements in vitamin A-depleted gerbils. The percentages of cassava used in these studies (15-45\%) encompass the contribution of staple foods to typical diets of developing countries, as well as providing a range of provitamin A intakes for the gerbils. The cassava was peeled and boiled to remove cyanogenic compounds similarly to many human food preparation methods ${ }^{(35)}$. Processing is known to increase the percentage of $c i s$ - $\beta$-carotene ${ }^{(36-38)}$, and in the present experiment the percentage increased from approximately 25 to $48 \%$, which is similar to the $30-52 \%$ range observed for ten genotypes of processed cassava ${ }^{(38)}$. Thus, the provitamin A content of gerbil feeds and ratio of cis-to-trans $\beta$-carotene did not vary substantially from human food preparations.

Expt 1 demonstrates that equivalent vitamin A status can be achieved from consuming cassava or supplementation with small daily amounts of $\beta$-carotene. Gerbils in the high- $\beta$-carotene cassava and $\beta$-carotene supplement groups were able to maintain or improve their vitamin A status over the 4-week treatment period compared to baseline and control groups. The calculated conversion factor for $\beta$-carotene dissolved in oil was $2 \cdot 8 \mu \mathrm{g} \beta$-carotene to $1 \mu \mathrm{g}$ retinol $(2 \cdot 8: 1)$, which was consistent with values determined in prior gerbil studies conducted in our laboratory, i.e. $2 \cdot 4-2 \cdot 9: 1^{(31,32,39)}$. Reported conversion factors for bioefficacy in man range from 938:1 in healthy American males ${ }^{(34)}$ to $2 \cdot 4-2 \cdot 7: 1$ in Indonesian children with marginal vitamin A status ${ }^{(8,34,40)}$. Conversion factors determined using vitamin A-depleted gerbils are most similar to factors determined in human subjects with low or depleted status, i.e. $2: 1-3 \cdot 8: 1^{(8,41,42)}$. In a review of studies determining the bioequivalence of $\beta$-carotene in man, Thurnham ${ }^{(34)}$ concluded that bioefficacy is greater when obtained using small amounts and in subjects with low vitamin A status. Gerbils show similarity in $\beta$-carotene metabolism to man and are less prone to the problems with human studies associated with assessment of vitamin A status, dietary provitamin A intake and health status (e.g. incidence of helminthes, subclinical infection, inflammation). Comparisons between human studies are further complicated due to effects of dose size and frequency, food preparation, food matrix and fat intake.

The bioconversion factor for provitamin A to vitamin $\mathrm{A}$ in cassava was $3 \cdot 7: 1$. This factor is consistent with $3 \cdot 5: 1$ determined for high-lycopene carrots fed at similar daily rates ${ }^{(43)}$. Another study found much larger bioconversion ratios with a variety of carrots (i.e. typical orange, purple and high $\beta$-carotene orange) ranging from 13 to $30: 1^{(33)}$, but daily provitamin A intake was 5- to 25-fold higher and the depletion period was 3 weeks shorter than the cassava and high-lycopene carrot studies. Bioconversion factors for maize range from $2 \cdot 1$ to $3 \cdot 3: 1$ in high- $\beta$-carotene, high- $\beta$-cryptoxanthin and highlutein and zeaxanthin maizes ${ }^{(31,39,44)}$. Although the conversion factor for high- $\beta$-carotene maize in one study was determined on an all-trans- $\beta$-carotene basis instead of a total provitamin A basis ${ }^{(31)}$, the conversion factors are similar to cassava in a vitamin A-depleted model.

Bioefficacy of cis- $\beta$-carotene is generally accepted to be less than the trans isomer, but this is based on few studies. Reported vitamin A values determined in gerbil and rat models range from 23 to $61 \%$ for 9 -cis- $\beta$-carotene and from 48 to $74 \%$ for 13 -cis- $\beta$-carotene ${ }^{(45)}$. However, bioconversion factors were similar for gerbils on cassava and high-lycopene carrot feeds with similar total $\beta$-carotene content, but different cis content, 48 and $2.5 \%$, respectively ${ }^{(43)}$. In the current study, cassava feeds contained $48 \%$ cis- $\beta$-carotene and the supplement was $<4 \%$, and yet cis- $\beta$-carotene in the liver was $3-8 \%$ regardless of treatment group. Therefore, no relationship between hepatic cis- $\beta$-carotene and dietary intake was observed. In the $\beta$-carotene supplement group, presence of $c i s$ isomers could be attributed to an artifact of analysis or to trans-to-cis isomerisation occurring in the body. The lack of hepatic cis isomers in gerbils receiving cassava may indicate poor absorption and utilisation ${ }^{(38,46)}$, cis-totrans isomerisation within the body ${ }^{(47)}$ or preferential conversion to vitamin A. These processes may also depend on the cis isomer configuration as cis-to-trans isomerisation and absorption efficiencies have been shown to differ between 13-cis and 9-cis ${ }^{(38,45-47)}$. For example, the predominant tissue $\beta$-carotene isomer in gerbils administered 13 -cis- $\beta$-carotene was all-trans- $\beta$-carotene, but in gerbils administered 9 -cis- $\beta$-carotene, the major isomer was 9 -cis- $\beta$-carotene ${ }^{(45)}$.

The lack of effect of the cis-to-trans ratio on bioconversion factors observed in gerbils fed similar amounts of $\beta$-carotene from cassava and carrot is inconsistent with the idea that the trans isomer has a substantially better vitamin A value. Small incremental feeding of cassava may allow for more efficient absorption and bioconversion of cis isomers. The daily doses administered in prior studies ${ }^{(45)}$ were $>$ four times higher than the $\beta$-carotene consumed from the cassava and carrot $^{(43)}$ feeds. Other factors such as vitamin A status, feeding mechanism and experimental duration also contribute to potential differences between studies. Due to the large cis content of raw (approximately 20-25\%) and processed (approximately $30-50 \%$ ) cassava, it is important to understand the contribution of cis- $\beta$-carotene to vitamin A pools when consumed as a staple food. If cis isomers are not as effective as trans, then strategies to improve provitamin A food sources may require targeting of the trans isomer during breeding and/or development of food preparation methods that minimise $c i s-\beta$-carotene production and maximise all-trans-bioavailability.

In Expt 2, the gerbil model maintained relatively constant liver stores of vitamin A in response to increasing carotenoid intake, and hepatic $\beta$-carotene increased. This moderating at adequate liver stores prevents hypervitaminosis $\mathrm{A}$ from provitamin A food sources ${ }^{(48)}$. In studies investigating the 
bioaccessibility of carotenoids from cassava, partitioning of $\beta$-carotene into micelles during digestion and accumulation of trans- $\beta$-carotene was linearly proportional to trans- $\beta$-carotene in cassava ${ }^{(38)}$. Furthermore, the accumulation of trans$\beta$-carotene by human Caco- 2 cells was proportional to the concentration in the micelles indicating that bioaccessibility is directly related to trans- $\beta$-carotene in cassava ${ }^{(38)}$. Because the gerbils in the current study were not deficient, bioconversion of $\beta$-carotene to vitamin A was reduced, more $\beta$-carotene was stored, and hepatic vitamin A did not differ with respect to the variable carotenoid content.

The depletion phase was not intended to initiate vitamin A deficiency, but designed to deplete vitamin A reserves. The white cassava feed contained $0.16 \mathrm{nmol} \beta$-carotene/g and theoretically provided $3 \mathrm{nmol}$ vitamin $\mathrm{A} / \mathrm{d}$ or a total of 84 nmol vitamin A for the 4-week depletion period. Comparing with baseline white maize groups from other similar studies $^{(31,39,43)}$, liver reserves were $7-54 \%$ greater in gerbils on the white cassava feed. Thus, the provitamin A content in the white cassava illustrates the contribution of consuming small, regular amounts of provitamin A to vitamin A status. More efficient bioconversion of provitamin A to vitamin A and/or to increased conservation of vitamin A occurs when vitamin $\mathrm{A}$ is limited. This phenomenon has been reported in human studies ${ }^{(34,49)}$, but is not incorporated into estimates of dietary conversion factors ${ }^{(4)}$.

The present study confirms that provitamin A carotenoids in cassava are as bioavailable as $\beta$-carotene supplements in a vitamin A-depleted gerbil model. Furthermore, results indicate that cis- $\beta$-carotene may be more efficacious than previously thought. Further studies are needed to fully determine the role of cis- $\beta$-carotene in maintaining vitamin A status and how it will affect breeding efforts. Bioconversion factors for cassava, high-lycopene carrots and maize in vitamin A-depleted gerbils are much lower than values proposed by the Institute of Medicine ${ }^{(4)}$ and are more likely representative of depleted or deficient human subjects. The present study demonstrates the potential for positively altering or maintaining vitamin A status using cassava with enhanced provitamin A carotenoids and indicates that evaluation in man should be pursued.

\section{Acknowledgements}

The authors have no conflicts of interest with the information presented in this paper. This work was supported by HarvestPlus contract number 8037 and Hatch Wisconsin Agricultural Experiment Station number WIS04975. J. A. H. co-wrote the grant proposal, performed the research, analysed the data and wrote the manuscript. B. M.-D. bred, grew and provided three cassava varieties. S. A. T. co-wrote the grant proposal and provided oversight and advice for the studies. All authors contributed to manuscript revision. The authors thank Amy Peterson, Julie Montagnac and Emily Ness for their excellent gerbil care, and Amy Peterson for her assistance with analysis.

\section{References}

1. Iglesias C, Mayer J, Chavez L, et al. (1997) Genetic potential and stability of carotene content in cassava roots. Euphytica 94, 367-373.
2. Chavez AL, Sanchez T, Jaramillo G, et al. (2005) Variation of quality traits in cassava roots evaluated in landraces and improved clones. Euphytica 143, 125-133.

3. Surles RL, Weng N, Simon PW, et al. (2004) Carotenoid profiles and consumer sensory evaluation of specialty carrots (Daucus carota L.) of various colors. J Agric Food Chem 52, 3417-3421.

4. Institute of Medicine Food and Nutrition Board (2000) Dietary Reference Intakes for Vitamin A, Vitamin K, Arsenic, Boron, Chromium, Copper, Iodine, Iron, Manganese, Molybdenum, Nickel, Silicon, Vanadium, and Zinc, pp. 325-382. Washington, DC: National Academy Press.

5. de Pee S, West CE, Permaesih D, et al. (1998) Orange fruit is more effective than are dark-green, leafy vegetables in increasing serum concentrations of retinol and $\beta$-carotene in schoolchildren in Indonesia. Am J Clin Nutr 68, 1058-1067.

6. Tanumihardjo SA (2002) Factors influencing the conversion of carotenoids to retinol: bioavailability to bioconversion to bioefficacy. Int $J$ Vitam Nutr Res 72, 40-45.

7. Faulks RM \& Southon S (2005) Challenges to understanding and measuring carotenoid bioavailability. Biochim Biophys Acta 1740, 95-100.

8. van Lieshout M, West CE, Muhilal, et al. (2001) Bioefficacy of $\beta$-carotene dissolved in oil studied in children in Indonesia. Am J Clin Nutr 73, 949-958.

9. Jayarajan P, Reddy V \& Mohanram M (1980) Effect of dietaryfat on absorption of beta-carotene from green leafy vegetables in children. Indian J Med Res 71, 53-56.

10. Jalal F, Nesheim MC, Agus Z, et al. (1998) Serum retinol concentrations in children are affected by food sources of $\beta$-carotene, fat intake, and anthelmintic drug treatment. Am J Clin Nutr 68, 623-629.

11. van het Hof K, West CE, Weststrate JA, et al. (2000) Dietary factors that affect the bioavailability of carotenoids. J Nutr 130, $503-506$.

12. Garrett DA, Failla ML \& Sarama RJ (1999) Development of an in vitro digestion method to assess carotenoid bioavailability from meals. J Agric Food Chem 47, 4301-4309.

13. Garrett DA, Failla ML \& Sarama RJ (2000) Estimation of carotenoid bioavailability from fresh stir-fried vegetables using an in vitro digestion/Caco-2 cell culture model. $J$ Nutr Biochem 11, 574-580.

14. Liu CS, Glahn RP \& Liu RH (2004) Assessment of carotenoid bioavailability of whole foods using a Caco-2 cell culture model coupled with an in vitro digestion. J Agric Food Chem 52, 4330-4337.

15. During A \& Harrison EH (2004) Intestinal absorption and metabolism of carotenoids: insights from cell culture. Arch Biochem Biophys 430, 77-88.

16. Kurilich AC, Britz SJ, Clevidence BA, et al. (2003) Isotopic labeling and LC-APCI-MS quantification for investigating absorption of carotenoids and phylloquinone from kale (Brassica oleracea). J Agric Food Chem 51, 4877-4883.

17. Vitamin A Tracer Task Force (members Furr HC, Green MH, Haskell M, Mokhtar N, Nestel P, Ribaya-Mercado J, Tanumihardjo SA, Wasantwisut E; lead drafters Tanumihardjo SA \& Nestel P) (2004) Appropriate Uses of Vitamin A Tracer (Stable Isotope) Methodology. Washington, DC: ILSI Human Nutrition Institute.

18. Ribaya-Mercado JD, Holmgren SC, Fox JG, et al. (1989) Dietary $\beta$-carotene absorption and metabolism in ferrets and rats. J Nutr 119, 665-668.

19. Krinsky NI, Mathewsroth MM, Welankiwar S, et al. (1990) The metabolism of $\left[{ }^{14} \mathrm{C}\right] \beta$-carotene and the presence of other carotenoids in rats and monkeys. J Nutr 120, 81-87.

20. Barua AB \& Olson JA (2000) $\beta$-Carotene is converted primarily to retinoids in rats in vivo. J Nutr 130, 1996-2001. 
21. Lee CM, Lederman JD, Hofmann NE, et al. (1989) The Mongolian gerbil (Meriones unguiculatus) is an appropriate animal model for evaluation of the conversion of $\beta$-carotene to vitamin A. J Nutr 128, 280-286.

22. Goodman DS \& Blaner WS (1984) Biosynthesis, absorption, and hepatic metabolism of retinol. In The Retinoids, vol. 2, pp. 1-39 [MB Sporn, AB Roberts and DS Goodman, editors]. Orlando, FL: Academic Press.

23. Pollack J, Campbell JM, Potter SM, et al. (1994) Mongolian gerbils (Meriones unguiculatus) absorb $\beta$-carotene intact from a test meal. J Nutr 124, 869-873.

24. House WA, Apgar J \& Smith JC (1997) The gerbil: a model for studying the metabolism of $\beta$-carotene and minerals. Nutr Res 17, 1293-1302.

25. Thatcher AJ, Lee CM \& Erdman JW Jr (1998) Tissue stores of $\beta$-carotene are not conserved for later use as a source of vitamin A during compromised vitamin A status in Mongolian gerbils (Meriones unguiculatus). J Nutr 128, 1179-1185.

26. Lee CM, Boileau AC, Boileau TWM, et al. (1999) Review of animal models in carotenoid research. J Nutr 129, 2271-2277.

27. Reeves PG, Forrest HN \& Fahey GC Jr (1993) AIN 93 purified diets for laboratory rodents: final report of the American Institute of Nutrition ad hoc writing committee on the reformulation of the AIN76A rodent diet. J Nutr 123, 1939-1951.

28. Howe JA \& Tanumihardjo SA (2006) Evaluation of analytical methods for carotenoid extraction from biofortified maize (Zea mays sp.). J Agric Food Chem 54, 7992-7997.

29. Moros EE, Darnoko D, Cheryan M, et al. (2002) Analysis of xanthophylls in corn by HPLC. J Agric Food Chem 50, 5787-5790.

30. Sharpless KE, Thomas JB, Sander LC, et al. (1996) Liquid chromatographic determination of carotenoids in human serum using an engineered C-30 and a C-18 stationary phase. J Chromatogr B: Biomed Appl 678, 187-195.

31. Howe JA \& Tanumihardjo SA (2006) Carotenoid-biofortified maize maintains adequate vitamin A status in Mongolian gerbils. J Nutr 136, 2562-2567.

32. Tanumihardjo SA \& Howe JA (2005) Twice the amount of $\beta$ carotene isolated from carrots is as effective as $\beta$-carotene in maintaining the vitamin A status of Mongolian gerbils. $J$ Nutr 135, 2622-2626.

33. Porter Dosti M, Mills JP, Simon PW, et al. (2006) Bioavailability of $\beta$-carotene $(\beta C)$ from purple carrots is the same as typical orange carrots while high- $\beta C$ carrots increase $\beta C$ stores in Mongolian gerbils (Meriones unguiculatus). $\mathrm{Br} J$ Nutr 96, 258-267.

34. Thurnham DI (2007) Bioequivalence of $\beta$-carotene and retinol. J Sci Food Agric 87, 13-39.

35. Montagnac JA, Davis CR \& Tanumihardjo SA (2009) Processing techniques to reduce toxicity and antinutrients of cassava for use as a staple food. Comp Rev Food Sci Food Safety (In the Press).
36. Aman R, Schieber A \& Carle R (2005) Effects of heating and illumination on trans-cis isomerization and degradation of $\beta$-carotene and lutein in isolated spinach chloroplasts. J Agric Food Chem 53, 9512-9518.

37. Rock CL, Lovalva JL, Emenhiser C, et al. (1998) Bioavailability of $\beta$-carotene is lower in raw than processed carrots and spinach in women. J Nutr 128, 913-916.

38. Thakkar SK, Maziya-Dixon B, Dixon AGOB-C, et al. (2007) Carotene micellarization during in vitro digestion and uptake by Caco- 2 cells is directly proportional to $\beta$-carotene content in different genotypes of cassava. J Nutr 137, 2229-2233.

39. Davis C, Jing H, Howe JA, et al. (2008) $\beta$-Cryptoxanthin from supplements or carotenoid-enhanced maize maintains liver vitamin A in Mongolian gerbils (Meriones unguiculatus) better than or equal to $\beta$-carotene supplements. Br J Nutr 100, 786-793.

40. van Lieshout $M$, West CE \& van Breemen RB (2003) Isotopic tracer techniques for studying the bioavailability and bioefficacy of dietary carotenoids, particularly $\beta$-carotene, in humans: a review. Am J Clin Nutr 77, 12-28.

41. Hume EM \& Krebs HA (1949) Vitamin A Requirement of Human Adults. An Experimental Study of Vitamin A Deprivation in Man. A Report of the Vitamin A Sub-Committee of the Accessory Food Factors Committee. Report no. 264. London: HMSO.

42. Sauberlich HE, Hodges RE, Wallace DL, et al. (1974) Vitamin A metabolism and requirements in the human studied with the use of labeled retinol. Vitam Horm 32, 251-275.

43. Mills JP, Simon PW \& Tanumihardjo SA (2007) $\beta$-Carotene from red carrot maintains vitamin A status, but lycopene bioavailability is lower relative to tomato paste in Mongolian gerbils. J Nutr 137, 1395-1400.

44. Davis CR, Howe JA, Rocheford TR, et al. (2008) The xanthophyll composition of biofortified maize (Zea mays sp.) does not influence the bioefficacy of provitamin A carotenoids in Mongolian gerbils (Meriones unguiculatus). J Agric Food Chem 56, 6745-6750.

45. Deming DM, Baker DH \& Erdman JW Jr (2002) The relative vitamin A value of 9-cis $\beta$-carotene is less and that of 13-cis $\beta$-carotene may be greater than the accepted $50 \%$ of all-trans $\beta$-carotene in gerbils. J Nutr 132, 2709-2712.

46. Tyssandier V, Reboul E, Dumas JF, et al. (2003) Processing of vegetable-borne carotenoids in the human stomach and duodenum. Am J Physiol Gastrointest Liver Physiol 284, G913-G923.

47. You CS, Parker RS, Goodman KJ, et al. (1996) Evidence of cistrans isomerization of 9-cis-beta-carotene during absorption in humans. Am J Clin Nutr 64, 177-183.

48. Tanumihardjo SA (2008) Food-based approaches for ensuring adequate vitamin A nutrition. Comp Rev Food Sci Food Safety 7, 373-381.

49. Tang GW, Qin J, Dolnikowski GG, et al. (2003) Short-term (intestinal) and long-term (postintestinal) conversion of $\beta$-carotene to retinol in adults as assessed by a stable-isotope reference method. Am J Clin Nutr 78, 259-266. 